\title{
Human $\mathrm{CO}_{2}$ Emissions Have Little Effect on Atmospheric $\mathrm{CO}_{2}$
}

\author{
Edwin X Berry \\ Climate Physics LLC, Bigfork, USA
}

Email address:

ed@edberry.com

To cite this article:

Edwin X Berry. Human $\mathrm{CO}_{2}$ Emissions Have Little Effect on Atmospheric $\mathrm{CO}_{2}$. International Journal of Atmospheric and Oceanic Sciences . Vol. 3, No. 1, 2019, pp. 13-26. doi: 10.11648/j.ijaos.20190301.13

Received: May 13, 2019; Accepted: June 12, 2019; Published: June 4, 2019

\begin{abstract}
The United Nations Intergovernmental Panel on Climate Change (IPCC) agrees human $\mathrm{CO}_{2}$ is only 5 percent and natural $\mathrm{CO}_{2}$ is 95 percent of the $\mathrm{CO}_{2}$ inflow into the atmosphere. The ratio of human to natural $\mathrm{CO}_{2}$ in the atmosphere must equal the ratio of the inflows. Yet IPCC claims human $\mathrm{CO}_{2}$ has caused all the rise in atmospheric $\mathrm{CO}_{2}$ above 280 ppm, which is now 130 ppm or 32 percent of today's atmospheric $\mathrm{CO}_{2}$. To cause the human 5 percent to become 32 percent in the atmosphere, the IPCC model treats human and natural $\mathrm{CO}_{2}$ differently, which is impossible because the molecules are identical. IPCC's Bern model artificially traps human $\mathrm{CO}_{2}$ in the atmosphere while it lets natural $\mathrm{CO}_{2}$ flow freely out of the atmosphere. By contrast, a simple Physics Model treats all $\mathrm{CO}_{2}$ molecules the same, as it should, and shows how $\mathrm{CO}_{2}$ flows through the atmosphere and produces a balance level where outflow equals inflow. Thereafter, if inflow is constant, level remains constant. The Physics Model has only one hypothesis, that outflow is proportional to level. The Physics Model exactly replicates the $14 \mathrm{C}$ data from 1970 to 2014 with only two physical parameters: balance level and e-time. The $14 \mathrm{C}$ data trace how $\mathrm{CO}_{2}$ flows out of the atmosphere. The Physics Model shows the $14 \mathrm{CO}_{2}$ e-time is a constant 16.5 years. Other data show e-time for $12 \mathrm{CO}_{2}$ is about 4 to 5 years. IPCC claims human $\mathrm{CO}_{2}$ reduces ocean buffer capacity. But that would increase e-time. The constant e-time proves IPCC's claim is false. IPCC argues that the human-caused reduction of $14 \mathrm{C}$ and $13 \mathrm{C}$ in the atmosphere prove human $\mathrm{CO}_{2}$ causes all the increase in atmospheric $\mathrm{CO}_{2}$. However, numbers show these isotope data support the Physics Model and reject the IPCC model. The Physics Model shows how inflows of human and natural $\mathrm{CO}_{2}$ into the atmosphere set balance levels proportional to their inflows. Each balance level remains constant if its inflow remains constant. Continued constant $\mathrm{CO}_{2}$ emissions do not add more $\mathrm{CO}_{2}$ to the atmosphere. No $\mathrm{CO}_{2}$ accumulates in the atmosphere. Present human $\mathrm{CO}_{2}$ inflow produces a balance level of about $18 \mathrm{ppm}$. Present natural $\mathrm{CO}_{2}$ inflow produces a balance level of about $392 \mathrm{ppm}$. Human $\mathrm{CO}_{2}$ is insignificant to the increase of $\mathrm{CO}_{2}$ in the atmosphere. Increased natural $\mathrm{CO}_{2}$ inflow has increased the level of $\mathrm{CO}_{2}$ in the atmosphere.
\end{abstract}

Keywords: Carbon Dioxide, $\mathrm{CO}_{2}$, Climate Change, Anthropogenic

\section{Introduction}

The U.S. Global Change Research Program Climate Science Special Report (USGCRP) [1] claims,

This assessment concludes, based on extensive evidence, that it is extremely likely that human activities, especially emissions of greenhouse gases, are the dominant cause of the observed warming since the mid-20th century.

The United Nations Intergovernmental Panel on Climate Change (IPCC) [2] Executive Summary claims human emissions caused atmospheric $\mathrm{CO}_{2}$ to increase from $280 \mathrm{ppm}$ in 1750 , to $410 \mathrm{ppm}$ in 2018 , for a total increase of $130 \mathrm{ppm}$.

IPCC and USGCRP claim there are "no convincing alternative explanations" other than their theory to explain the "observational evidence."

This paper presents a "convincing alternative explanation" that explains the data. A simple physics model explains the required first step of human-caused climate change: how human $\mathrm{CO}_{2}$ changes atmospheric $\mathrm{CO}_{2}$.

For simplicity, this paper uses levels in units of ppm (parts per million by volume in dry air) and flows in units of ppm per year. GtC (Gigatons of Carbon) units are converted into $\mathrm{CO}_{2}$ units in ppm using:

$$
1 \mathrm{ppm}=2.12 \mathrm{GtC}
$$

Authors who support the USGCRP [1] and IPCC [2, 3] 
include Archer et al. [4], Cawley [5], Kern and Leuenberger [6], and Kohler [7].

Authors who conclude human $\mathrm{CO}_{2}$ increases atmospheric $\mathrm{CO}_{2}$ as a percentage of its inflow include Revelle and Suess [8], Starr [9], Segalstad [10], Jaworoski [11, 12], Beck [13], Rorsch, Courtney, and Thoenes [14], Courtney [15], Quirk [16], Essenhigh [17], Glassman [18], Salby [19-22], Humlum [23], Harde [24, 25], and Berry [26, 27].

\section{The Science Problem}

IPCC $[2,3]$ says nature emits about $120 \mathrm{GtC}$ from land and $90 \mathrm{GtC}$ from ocean for a total of $210 \mathrm{GtC}$ per year. This is equivalent to about $98 \mathrm{ppm}$ per year of natural $\mathrm{CO}_{2}$ that flows into the atmosphere. IPCC admits its estimates of "gross fluxes generally have uncertainties of more than $\pm 20 \%$."

Boden [28] shows human $\mathrm{CO}_{2}$ emissions in 2014 were 9.7 GTC per year, or $4.6 \mathrm{ppm}$ per year. So, IPCC agrees that human inflow is less than $5 \%$ and nature is more than $95 \%$ of the total $\mathrm{CO}_{2}$ inflow into the atmosphere. Yet IPCC assumes nature stayed constant since 1750 and human $\mathrm{CO}_{2}$ causes 100 percent the increase in atmospheric $\mathrm{CO}_{2}$ above $280 \mathrm{ppm}$, which today is $130 \mathrm{ppm}$ or 32 percent of $410 \mathrm{ppm}$.

The Physics Model concludes the percent of human $\mathrm{CO}_{2}$ in the atmosphere equals the percent of human $\mathrm{CO}_{2}$ in the inflow.

Figure 1 shows how the predictions of the Physics Model and IPCC model differ regarding the composition of human $\mathrm{CO}_{2}$ in the atmosphere.

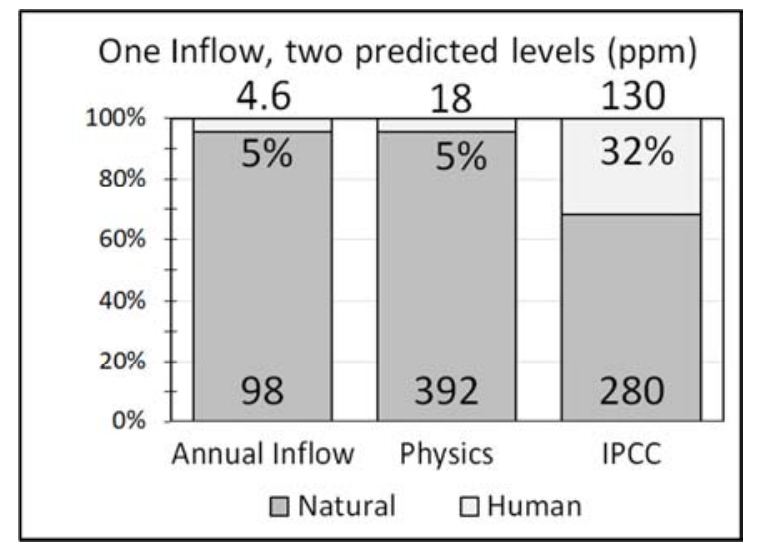

Figure 1. The IPCC agrees the inflow of human $\mathrm{CO}_{2}$ is less than 5 percent. The Physics Model says the percent of human $\mathrm{CO}_{2}$ in the atmosphere equals the percent of its inflow. IPCC claims human $\mathrm{CO}_{2}$ adds all atmospheric $\mathrm{CO}_{2}$ above 280 ppm, which is now 32 percent of the total.

If the IPCC model is correct, then the effect of human $\mathrm{CO}_{2}$ emissions on atmospheric $\mathrm{CO}_{2}$ is 100 percent. If the Physics Model is correct, then human $\mathrm{CO}_{2}$ emissions do not cause climate change.

\section{The Physics Model}

\subsection{How $\mathrm{CO}_{2}$ Flows Through the Atmosphere}

IPCC states, and much of the public believes, human emissions "add" $\mathrm{CO}_{2}$ to the atmosphere. IPCC's view is the atmosphere is a garbage dump where human $\mathrm{CO}_{2}$ is deposited and mostly stays forever.

However, nature must treat human and natural $\mathrm{CO}_{2}$ the same because their molecules are identical. Nature has had millions of years to "add" to atmospheric $\mathrm{CO}_{2}$. If nature's $\mathrm{CO}_{2}$ "adds" to atmospheric $\mathrm{CO}_{2}$, the $\mathrm{CO}_{2}$ in the atmosphere would be much higher than it is today.

Therefore, natural and human $\mathrm{CO}_{2}$ do not "add" $\mathrm{CO}_{2}$ to the atmosphere. Both natural and human $\mathrm{CO}_{2}$ "flow through" the atmosphere. As $\mathrm{CO}_{2}$ flows through the atmosphere, it raises the level of atmospheric $\mathrm{CO}_{2}$ just enough so $\mathrm{CO}_{2}$ outflow equals $\mathrm{CO}_{2}$ inflow. Nature balances $\mathrm{CO}_{2}$ in the atmosphere when outflow equals inflow.

You pump air into a tire or inner tube that has a leak. As you pump air into the tube, air leaks out of the tube. The faster you pump air in, the faster air leaks out. If you pump air into the tube at a constant rate, the air pressure in the tube will find a level where outflow equals inflow.

River water flows into a lake or a pond and flows out over a dam. If inflow increases, the water level increases until outflow over the dam equals inflow from the river. Then, the water level will remain constant so long as inflow remains constant. The river does not "add" water to the lake. Water "flows through" the lake and finds a balance level where outflow equals inflow.

Similarly, human and natural $\mathrm{CO}_{2}$ flow through the atmosphere. The inflow creates a balance level that remains constant so long as inflow remains constant.

\subsection{Physics Model System Description}

Figure 2 shows a bucket of water as an analogy to $\mathrm{CO}_{2}$ in the atmosphere. Water flows into the bucket at the top and flows out through a hole in the bottom. An outside source (faucet) controls the inflow.

The water level and the hole size control the outflow. No matter what the inflow, the level and the size of the hole control the outflow. Inflow only serves to set a balance level.

This paper uses e-time rather than "residence" time because there are many definitions of residence time. E-time has a precise definition: the time for the level to move $(1-1 / \mathrm{e})$ of the distance from its present level to its balance level. The balance level is defined below.

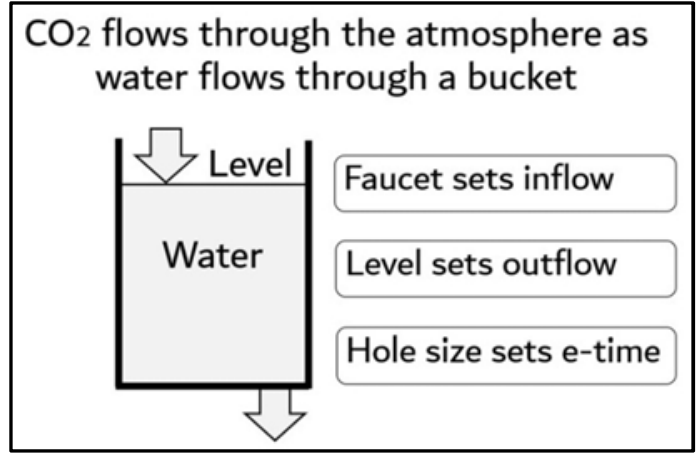

Figure 2. A bucket of water is an analogy to the Physics Model for atmospheric $\mathrm{CO}_{2}$. Water flows through the bucket as $\mathrm{CO}_{2}$ flows through the atmosphere. 
The bucket analogy provides insight into e-time. If the hole in the bucket gets smaller, e-time increases. If the hole in the bucket gets larger, e-time decreases. The hole is an analogy to the ability of the oceans and land to absorb $\mathrm{CO}_{2}$ from the atmosphere.

Figure 3 shows the Physics Model system for atmospheric $\mathrm{CO}_{2}$. The system includes the level (concentration) of $\mathrm{CO}_{2}$ in the atmosphere and the inflow and outflow of $\mathrm{CO}_{2}$.

\section{$\mathrm{CO}_{2}$ flows through the Atmosphere}

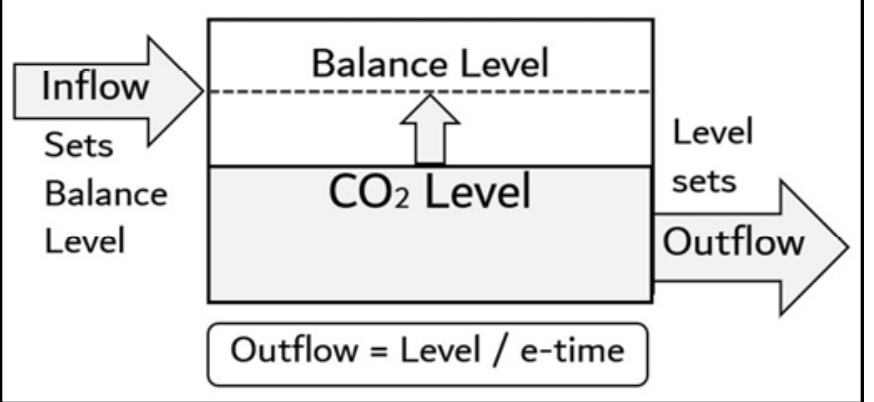

Figure 3. The Physics Model system for atmospheric $\mathrm{CO}_{2}$. Inflow and Outflow determine the change in level. The only hypothesis is Outflow $=$ Level /e-time.

The Physics Model applies independently and in total to all definitions of $\mathrm{CO}_{2}$, e.g., to human $\mathrm{CO}_{2}$, natural $\mathrm{CO}_{2}$, and their sums, and to $12 \mathrm{CO}_{2}, 13 \mathrm{CO}_{2}$, and $14 \mathrm{CO}_{2}$, and their sums.

The Physics Model is complete. It is not necessary to add separate inflows for human and natural $\mathrm{CO}_{2}$ to the Physics Model. Just use a copy of the Physics Model for each $\mathrm{CO}_{2}$ definition desired.

The Physics Model does not need to describe the details of the external processes. Inflow, outflow, and e-time include all the effects of outside processes. If the Physics Model were connected to land and ocean reservoirs, it would behave exactly as derived in this paper.

Kohler [7] claims Harde's [24] model and therefore the Physics Model is "too simplistic" and "leads to flawed results for anthropogenic carbon in the atmosphere."

Kohler is wrong. There is no such thing as a system being "too simplistic." A system should be as simple as possible to solve a problem. The Physics Model shows how inflow, outflow, and e-time affect the level of $\mathrm{CO}_{2}$ in the atmosphere. The IPCC model cannot do this.

\subsection{Physics Model Derivation}

A system describes a subset of nature. A system includes levels and flows between levels. Levels set flows and flows set new levels. The mathematics used in the Physics Model are analogous to the mathematics used to describe many engineering systems.

The Physics Model derivation begins with the continuity equation (1) which says the rate of change of level is the difference between inflow and outflow:

$$
d L / d t=\text { Inflow }- \text { Outflow }
$$

Where

$L=\mathrm{CO}_{2}$ level (concentration in ppm)

$t=$ time (years)

$d L / d t=$ rate of change of $L(\mathrm{ppm} /$ year $)$

Inflow $=$ rate $\mathrm{CO}_{2}$ moves into the system (ppm/year)

Outflow $=$ rate $\mathrm{CO}_{2}$ moves out of the system (ppm/year)

Following the idea from the bucket of water, the Physics Model has only one hypothesis, that outflow is proportional to level:

$$
\text { Outflow }=L / T e
$$

where Te is the "e-folding time" or simply "e-time."

Substitute (2) into (1) to get,

$$
d L / d t=\text { Inflow }-L / T e
$$

One way to replace Inflow in (3) is to set $\mathrm{dL} / \mathrm{dt}$ to zero, which means the level is constant. Then Inflow will equal a balance level, $L b$, divided by e-time. However, a more elegant way to replace Inflow is to simply define the balance level, $L b$, as

$$
L b=\text { Inflow }^{*} T e
$$

Equation (4) shows how Inflow and Te set the balance level. Substitute (4) for Inflow into (3) to get,

$$
d L / d t=-(L-L b) / T e
$$

Equation (5) shows the level always moves toward its balance level. At this point, both $L$ and $L b$ are functions of time. $T e$ can also be a function of time.

In the special case when $L b$ and $T e$ are constant, there is an analytic solution to (5). Rearrange (5) to get

$$
d L /(L-L b)=-d t / T e
$$

Then integrate (6) from $L o$ to $L$ on the left side, and from 0 to $t$ on the right side [29] to get

$$
\operatorname{Ln}[(L-L b) /(L o-L b)]=-t / T e
$$

where

$L o=$ Level at time zero $(t=0)$

$L b=$ the balance level for a given inflow and $T e$

$T e=$ time for $L$ to move $(1-1 /$ e) from $L$ to $L b$

$\mathrm{e}=2.7183$

The original integration of (6) contains two absolute values, but they cancel each other because both $L$ and $L o$ are always either above or below $L b$.

Raise e to the power of each side of (7), to get the level as a function of time:

$$
L(t)=L b+(L o-L b) \exp (-\mathrm{t} / T e)
$$

Equation (8) is the analytic solution of (5) when $L b$ and $T e$ are constant.

The hypothesis (2) that outflow is proportional to level creates a "balance level." Equation (4) defines the balance level in terms of inflow and e-time.

Figure 4 shows how the level always moves toward its 
balance level according to (5). While outflow is always proportional to level, inflow sets the balance level.

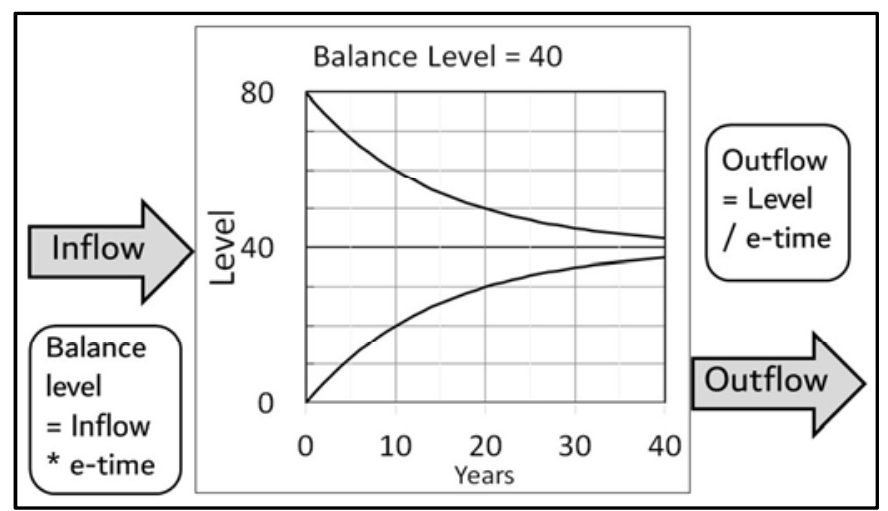

Figure 4. Inflow sets the balance level. The level at any time t determines the outflow. Level always moves toward the balance level, whether the level is above or below the balance level.

The Physics Model shows how $\mathrm{CO}_{2}$ flows through the atmosphere. $\mathrm{CO}_{2}$ does not "stick" in the atmosphere. A higher inflow merely raises the balance level. Then the level will rise until outflow equals inflow, which will be at the balance level.

\subsection{Physics Model Consequences}

All equations after (2) are deductions from hypothesis (2) and the continuity equation (1).

Equation (4) shows the balance level equals the product of inflow and e-time. Using IPCC numbers, and subscripts " $p$ " to mean human (or people) and " $n$ " to mean natural, the balance levels of human and natural $\mathrm{CO}_{2}$ are 18.4 and 392 ppm:

$$
\begin{aligned}
& L b p=4.6(\mathrm{ppm} / \text { year }) * 4(\text { years })=18.4 \mathrm{ppm} \\
& L b n=98(\mathrm{ppm} / \text { year }) * 4(\text { years })=392 \mathrm{ppm}
\end{aligned}
$$

The ratio of human to natural $\mathrm{CO}_{2}$ is $4.6 \%$. The percentage of human $\mathrm{CO}_{2}$ to total $\mathrm{CO}_{2}$ is $4.5 \%$. Both are independent of e-time:

$$
\begin{gathered}
L b p / L b n=4.6 / 98=4.6 \% \\
L b p /(L b n+L b p)=4.6 / 102.6=4.5 \%
\end{gathered}
$$

Equation (9) shows present human emissions create a balance level of $18 \mathrm{ppm}$, independent of nature's balance level. If nature's balance level remained at $280 \mathrm{ppm}$ after 1750 , then present human emissions would have increased the $\mathrm{CO}_{2}$ level $18 \mathrm{ppm}$ from $280 \mathrm{ppm}$ to $298 \mathrm{ppm}$.

Equation (10) shows present natural emissions create a balance level of $392 \mathrm{ppm}$. The human contribution of $18 \mathrm{ppm}$ brings the total balance level to $410 \mathrm{ppm}$, which is close to the level in 2018.

Equation (11) shows the ratio of human to natural $\mathrm{CO}_{2}$ in the atmosphere equals the ratio of their inflows, independent of e-time.

Equation (12) shows the percentage of human-produced $\mathrm{CO}_{2}$ in the atmosphere equals its percentage of its inflow, independent of e-time.
Figure 5 illustrates these Physics Model conclusions when e-time is 4 years.

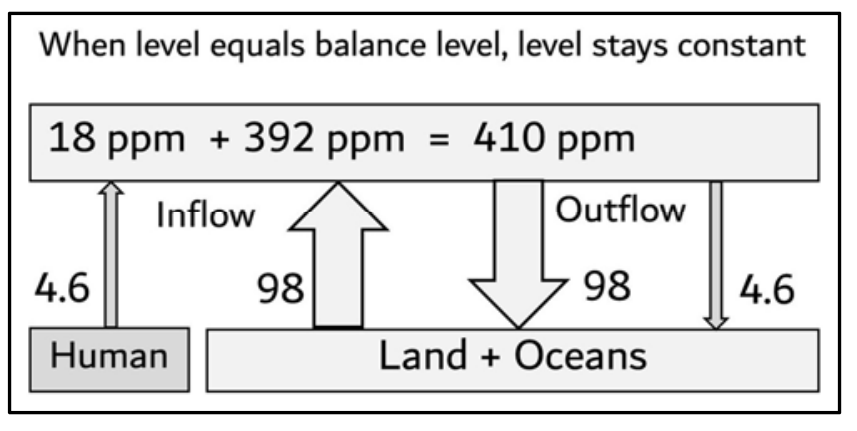

Figure 5. For an e-time of 4 years, the human inflow of 4.6 ppm per year sets a balance level of $18 \mathrm{ppm}$, and the natural inflow of $98 \mathrm{ppm}$ per year sets a balance level of $392 \mathrm{ppm}$. When the level equals the total balance level of 410 ppm, outflow will equal inflow and level will be constant.

Equations (9) and (10) support the key conclusions of Harde [24, 25]:

Under present conditions, the natural emissions contribute $373 \mathrm{ppm}$ and anthropogenic emissions $17 \mathrm{ppm}$ to the total concentration of $390 \mathrm{ppm}$ (2012).

\section{The IPCC Bern Model}

\subsection{IPCC Bern Model Origin}

In 1992, Siegenthaler and Joos [30] created the original Bern model. Their Figure 1 connects the atmosphere level to the upper ocean level, and the upper ocean level to the deep and interior ocean levels. They used $14 \mathrm{C}$ data to trace the flow of $12 \mathrm{CO}_{2}$ from the atmosphere to the upper ocean and to the deep and interior oceans. Using some physics constraints, they attempted without success to fit three versions of their model to available data.

Earlier, in 1987, Maier-Reimer and Hasselmann [31] used an ocean circulation model connected to a one-layer atmosphere to reproduce the main features of the $\mathrm{CO}_{2}$ distribution in the surface ocean. They applied a mathematical curve fit to represent their conclusions. Their curve fit used a sum of four exponentials with different amplitudes and time constants, as in today's Bern model.

The use of four exponentials by [31] seems to result from their reconnection of both the deep and interior ocean levels directly to the atmosphere level. Such reconnection would be a serious modelling mistake. Other papers followed the model developed by [31].

Archer et al. [4] found the four-exponential models "agreed that $20-35 \%$ of the $\mathrm{CO}_{2}$ remains in the atmosphere after equilibration with the ocean (2-20 centuries)."

Joos et al. [32] compared the response of such atmosphere-ocean models to a pulse emission of human $\mathrm{CO}_{2}$. All the models predicted a "substantial fraction" of pulse would remain in the atmosphere and ocean for millennia.

The conclusions of $[4,30,31,32]$ must be questioned because:

1. Agreement among models does not prove they are 
accurate.

2. All models treat human and natural $\mathrm{CO}_{2}$ differently, which violates physics.

3. All models assume human $\mathrm{CO}_{2}$ causes all the increase in atmospheric $\mathrm{CO}_{2}$, which violates physics.

4. All models partition human $\mathrm{CO}_{2}$ inflow into four artificial bins, which is unphysical.

5. All models lack a valid physics model for atmospheric $\mathrm{CO}_{2}$.

Segalstad [10] notes that the models like [31] do not allow $\mathrm{CO}_{2}$ to flow out of the atmosphere in linear proportion to the $\mathrm{CO}_{2}$ level. Rather they use a non-linear constraint on the outflow that contradicts physics and chemistry.

Segalstad [10] concludes the alleged long residence time of 500 years for carbon to diffuse to the deep ocean is inaccurate because the $1000 \mathrm{GtC}$ of suspended organic carbon in the upper 75 meters of the ocean can sink to the deep ocean in less than one year. That gives a residence time of 5 years rather than 500 years.

The IPCC Bern model that evolved from models like [31] artificially partitions human $\mathrm{CO}_{2}$ into four separate bins. The separate bins prevent human $\mathrm{CO}_{2}$ in one bin from moving to a bin with a faster e-time. This is like having three holes of different sizes in the bottom of a bucket and claiming the smallest hole restricts the flow through the largest hole.

The IPCC Bern model is unphysical. It begins with the assumption that human $\mathrm{CO}_{2}$ causes all the increase in atmospheric $\mathrm{CO}_{2}$. Then it creates a model that supports this assumption.

The Bern model fails Occam's Razor because it is unnecessarily complicated.

\subsection{IPCC Bern Model Derivation}

The Joos [33] Bern model is an integral equation rather than a level equation.

It is necessary to peer inside IPCC's Bern model. To deconstruct the integral version of the Bern model, let inflow occur only in the year when "t-prime" equals zero. Then the integral disappears, and the Bern model becomes a level equation.

The Bern level equation is,

$$
\begin{gathered}
L(t)=L o\left[A_{0}+A_{1} \exp \left(-t / T_{1}\right)+A_{2} \exp \left(-t / T_{2}\right)+\right. \\
\left.\mathrm{A}_{3} \exp \left(-t / T_{3}\right)\right]
\end{gathered}
$$

Where

$t=$ time in years

$L o=$ level of atmospheric $\mathrm{CO}_{2}$ in year $t=0$

$L(t)=$ level of atmospheric $\mathrm{CO}_{2}$ in year $t$

and the Bern TAR standard values, derived from curve-fitting the Bern model to the output of climate models, are,

$$
\begin{aligned}
& A_{0}=0.150 \\
& A_{1}=0.252 \\
& A_{2}=0.279 \\
& A_{3}=0.319 \\
& T_{1}=173 \text { years }
\end{aligned}
$$

$T_{2}=18.5$ years
$T_{3}=1.19$ years

The $A$-values weight the four terms on the right-hand side of (13):

$$
A_{0}+A_{1}+A_{2}+A_{3}=1.000
$$

In (13), set t equal to infinity to get,

$$
L=A_{0} L o=0.152 L o
$$

Equation (14) predicts a one-year inflow that sets Lo to 100 ppm, followed by zero inflow forever, will cause a permanent level of $15 \mathrm{ppm}$.

The four terms in (13) separate human (but not natural) $\mathrm{CO}_{2}$ into 4 bins. Each bin has a different e-time. Only one bin allows human $\mathrm{CO}_{2}$ to flow freely out of the atmosphere. Two bins trap human $\mathrm{CO}_{2}$ for long times. One bin has no outflow and traps human $\mathrm{CO}_{2}$ forever.

Figure 6 shows the size of the four Bern-model bins in percent and the amount of human $\mathrm{CO}_{2}$ that remains in the atmosphere 8 years after an artificial pulse of human $\mathrm{CO}_{2}$ enters the atmosphere.

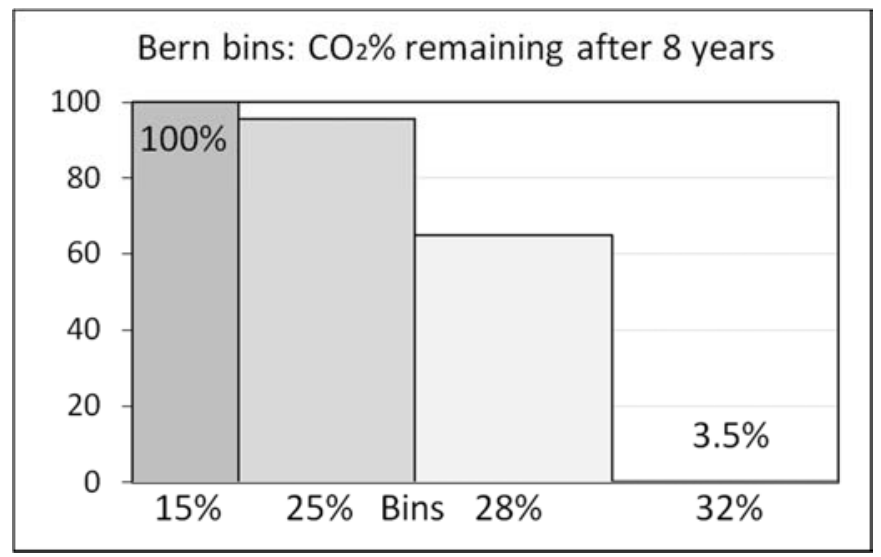

Figure 6. The percent of human $\mathrm{CO}_{2}$ left in each Bern model bin after 8 years.

Bern (13) predicts 15 percent all human $\mathrm{CO}_{2}$ entering the atmosphere stays in the atmosphere forever, 25 percent stays in the atmosphere almost forever, and only 32 percent flows freely out of the atmosphere.

\subsection{How IPCC Gets 32 Percent}

The burden of proof is upon the IPCC to explain how 5 percent human inflow becomes 32 percent in the atmosphere. IPCC cannot change the inflow. Therefore, IPCC must change the outflow. The IPCC Bern model restricts the outflow of human $\mathrm{CO}_{2}$ while it lets natural $\mathrm{CO}_{2}$ flow freely out of the atmosphere. The IPCC Bern model incorrectly treats human $\mathrm{CO}_{2}$ differently than it treats natural $\mathrm{CO}_{2}$. By doing so, it artificially increases human $\mathrm{CO}_{2}$ in the atmosphere to 32 percent and beyond.

IPCC assumes its Bern model applies to human but not to natural $\mathrm{CO}_{2}$. That assumption is unphysical because $\mathrm{CO}_{2}$ molecules from human and natural sources are identical. All valid models must treat human and natural $\mathrm{CO}_{2}$ the same.

If applied to natural $\mathrm{CO}_{2}$, the Bern model predicts 15 
percent of natural $\mathrm{CO}_{2}$ sticks in the atmosphere. Then in 100 years, $1500 \mathrm{ppm}$ of natural $\mathrm{CO}_{2}$ sticks in the atmosphere. This clearly has not happened. Therefore, the Bern model is invalid.

For you mathematicians:

It is simple to prove the Bern model is unphysical. Take the derivative of (13) with respect to time. It is impossible to get rid of the exponential terms because the Bern model has more than one time constant in its exponentials. The Bern model $\mathrm{dL} / \mathrm{dt}$ does not correspond to a physics formulation of a problem.

By contrast, it is straightforward to take the time derivative of the Physics Model (8) and reproduce its $\mathrm{dL} / \mathrm{dt}$ form of (5).

The Physics Model began as a rate equation, as all physics models should. The Bern model began with a curve fit to an imaginary scenario for a level rather than as a rate equation for a level. The Bern model does not even include a continuity equation.

\section{Theories Must Replicate Data}

\subsection{The 14C Data}

The above-ground atomic bomb tests in the 1950s and 1960 s almost doubled the concentration of $14 \mathrm{C}$ in the atmosphere. The $14 \mathrm{C}$ atoms were in the form of $\mathrm{CO}_{2}$, called $14 \mathrm{CO}_{2}$.

After the cessation of the bomb tests in 1963, the concentration of $14 \mathrm{CO}_{2}$ decreased toward its natural balance level. The decrease occurred because the bomb-caused $14 \mathrm{C}$ inflow became zero while the natural $14 \mathrm{C}$ inflow continued.

The $14 \mathrm{C}$ data are in units of D14C per mil. The lower bound in D14C units is -1000 . This value corresponds to zero $14 \mathrm{C}$ inflow into the atmosphere. In D14C units, the "natural" balance level, defined by the average measured level before 1950, is zero, 1000 up from -1000. [34].

Hua [34] processed $14 \mathrm{C}$ data for both hemispheres from 1954 to 2010. Turnbull [35] processed 14C data for Wellington, New Zealand, from 1954 to 2014. After 1970, $14 \mathrm{CO}_{2}$ were well mixed between the hemispheres and $14 \mathrm{CO}_{2}$ in the stratosphere were in the troposphere. The $14 \mathrm{C}$ data from both sources are virtually identical after 1970 .

$14 \mathrm{C}$ is an isotope of $12 \mathrm{C}$. Levin et al. [36] conclude the $\mathrm{C} 14$ data provide "an invaluable tracer to gain insight into the carbon cycle dynamics."

\subsection{Physics Model Replicates the 14C Data}

The Physics Model (8) accurately replicates the $14 \mathrm{CO}_{2}$ data from 1970 to 2014 with e-time set to 16.5 years, balance level set to zero, and starting level set to the D14C level in 1970.

Figure 7 shows how the Physics Model replicates the 14C data.

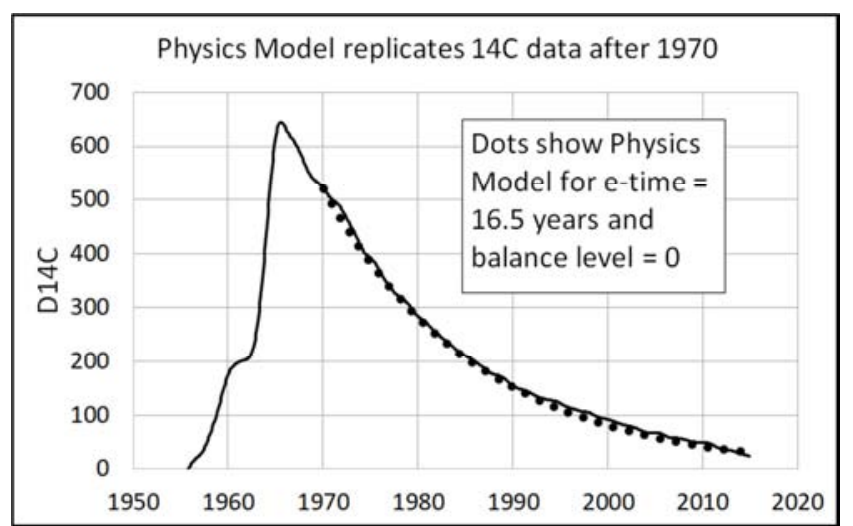

Figure 7. The 14C data from Turnbull [35] using 721 data points. The dotted line is the Physics Model replication of the data.

The Physics Model is not a curve fit with many parameters like the Bern model. The Physics model allows only 2 parameters to be adjusted: balance level and e-time, and they are both physical parameters. It is possible that the data would not allow replication by the Physics Model.

The replication of the $14 \mathrm{C}$ data begins by setting the Physics Model to the first data point in 1970. Then it is a matter of trying different balance levels and e-times until the model best fits the data. Although there is room for minor differences in the fit, the best fit seems to occur when the balance level is zero and e-time is 16.5 years.

The replication of the $14 \mathrm{C}$ data by the Physics Model has significant consequences. It shows the $14 \mathrm{C}$ natural balance level has remained close to zero and e-time has remained constant since 1970. If the e-time had changed since 1970, it would have required a variable e-time to make the Physics Model fit the data.

\section{3. $12 \mathrm{CO}_{2}$ Reacts Faster Than $14 \mathrm{CO}_{2}$}

Isotopes undergo the same chemical reactions but the rates that isotopes react can differ. Lighter isotopes form weaker chemical bonds and react faster than heavier isotopes [37].

Because $12 \mathrm{CO}_{2}$ is a lighter molecule than $14 \mathrm{CO}_{2}$, it reacts faster than $14 \mathrm{CO}_{2}$. Therefore, its e-time will be shorter than for $14 \mathrm{CO}_{2}$.

Equation (4) shows e-time equals Level divided by Inflow. Using IPCC numbers, e-time for $12 \mathrm{CO}_{2}$ is about $400 \mathrm{ppm}$ divided by 100 ppm per year, or 4 years. Also, IPCC [3] agrees $12 \mathrm{CO}_{2}$ turnover time (e-time) is about 4 years. Segalstad [10] calculated 5 years for e-time.

Figure 8 shows the Physics Model (8) simulation of $12 \mathrm{CO}_{2}$ using an e-time of 4 years. For comparison, Figure 8 shows the $14 \mathrm{C}$ data from Hua [34] and the Physics Model replication of $14 \mathrm{CO}_{2}$ data with an e-time of 16.5 . 


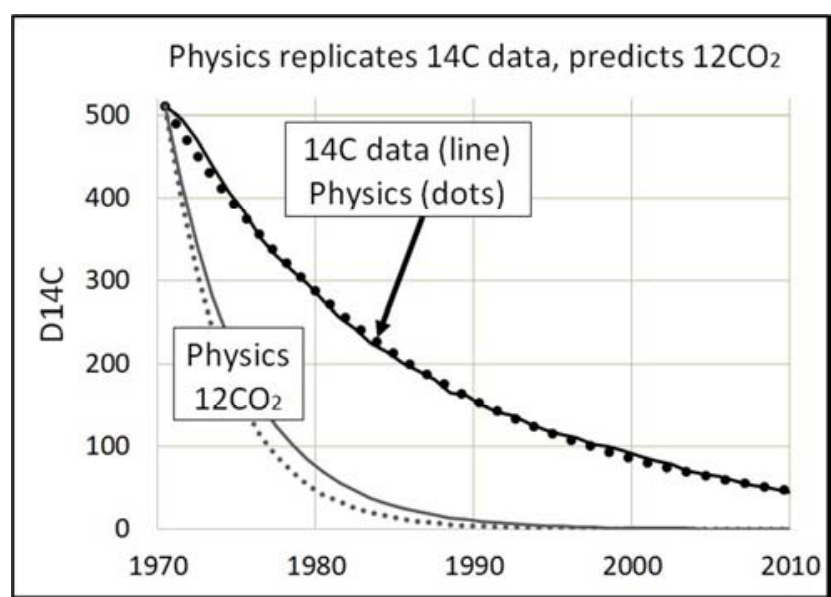

Figure 8. This plot uses the 14C data from Hua [34] from 1970 to 2010. Hua data is in mid-years, so the fit begins in 1970.5. The Physics Model (dotted line) replicates the $14 \mathrm{CO}_{2}$ data with an e-time of 16.5 years. The Physics Model simulates $12 \mathrm{CO}_{2}$ for an e-time of 4 years (dotted line) and 5 years (solid line).

\subsection{IPCC Model Cannot Simulate $12 \mathrm{CO}_{2}$}

The Bern model claims to predict the outflow of $12 \mathrm{CO}_{2}$. Therefore, the Bern model should come close to predicting the outflow of $12 \mathrm{CO}_{2}$ as calculated by the Physics Model that replicates the $14 \mathrm{C}$ data.

Figure 9 shows the Bern model (13) predictions. The IPCC Bern model begins with a short e-time, then increases its e-time. The increased e-time causes the Bern line to cross the $14 \mathrm{C}$ line and thus conflicts with the $14 \mathrm{C}$ data. The Bern model traps 15 percent of human $\mathrm{CO}_{2}$ in the atmosphere forever.

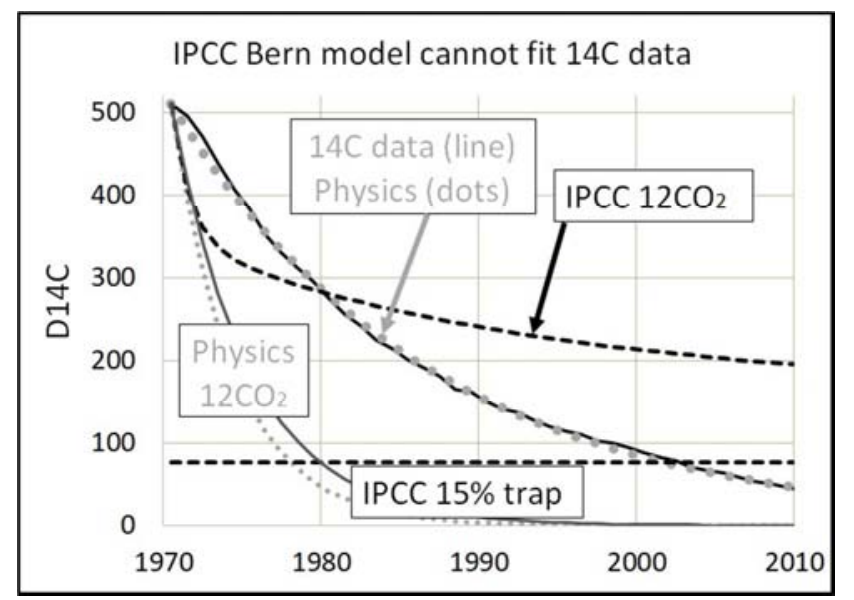

Figure 9. The IPCC Bern model (dashed lines) is not consistent with the $12 \mathrm{CO}_{2}$ simulation or with $14 \mathrm{CO}_{2}$ data. The Bern model includes a trap for 15 percent of human $\mathrm{CO}_{2}$.

The IPCC Bern model is not just a failure to simulate data. The Bern model is a functional failure. It's e-time increases significantly with time when $14 \mathrm{C}$ data show e-time is constant. The only way the Bern model can increase with time is by using its history as a reference.

Figure 10 shows how the IPCC Bern model cannot even replicate itself when it is restarted at any point in its simulation.

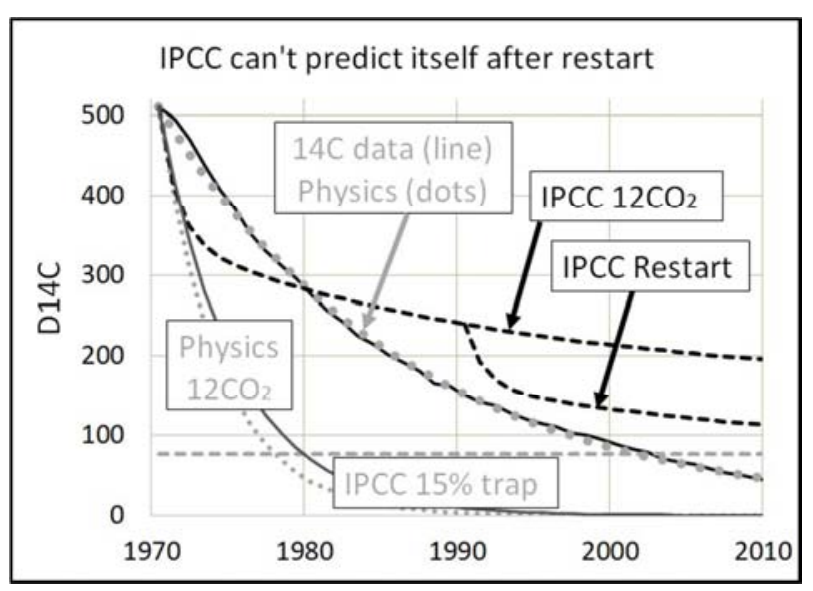

Figure 10. The Bern model (dashed lines) cannot even replicate itself after a restart.

The IPCC Bern model cannot continue its same prediction line if it is restarted at any point. The Bern model cannot properly restart because it depends upon its history, which makes it an invalid model.

A restart deletes the Bern model's history. This forces the Bern model to create a new history. In the real world, molecules do not remember their history. Molecules only know their present. Therefore, the IPCC Bern model fails the most basic test for a physical model.

Revelle and Suess [8] used 14C data to calculate correctly that human $\mathrm{CO}_{2}$ would increase atmospheric $\mathrm{CO}_{2}$ by only 1.2 percent as of 1957, based for an e-time of 5 years.

\subsection{IPCC's Buffer Theory is Invalid}

\section{IPCC [3] claims:}

The fraction of anthropogenic $\mathrm{CO}_{2}$ that is taken up by the ocean declines with increasing $\mathrm{CO}_{2}$ concentration, due to reduced buffer capacity of the carbonate system.

Buffer capacity is the ability of the oceans to absorb $\mathrm{CO}_{2}$.

Kohler et al. [7] claim human (but not natural) $\mathrm{CO}_{2}$ has reduced the "buffer capacity" of the carbonate system:

The rise in atmospheric and oceanic carbon content goes along with an increase in the Revelle factor, a phenomenon which is already measurable. This implies that the oceanic uptake of anthropogenic carbon will become slower if we continue to increase anthropogenic $\mathrm{CO}_{2}$ emissions. This is already seen in all CHIMP5 model simulations.

Kohler's last sentence exhibits circular reasoning when it claims a model can prove what has been fed into the model.

All IPCC models use the buffer factor myth instead of Henry's Law to conclude human $\mathrm{CO}_{2}$ causes all the rise in atmospheric $\mathrm{CO}_{2}[10]$.

The problem for Kohler and IPCC is data. Where are the data that support their claim? They have only their models. Models are not data. Models must make predictions that replicate data. Their models cannot replicate data.

Ballantyne et al. [38] found "there is no empirical evidence" that the ability of the land and oceans to absorb atmospheric $\mathrm{CO}_{2}$ "has started to diminish on the global scale." 
The 14C data are the most accurate way to measure changes in the Revelle factor and "buffer capacity." Reduced buffer capacity, if it existed, would increase e-time. The 14C data prove e-time has been constant since 1970. Therefore, IPCC's buffer capacity has been constant.

IPCC's buffer capacity claim is absurd because it assumes only human $\mathrm{CO}_{2}$ reduces the buffer capacity while natural $\mathrm{CO}_{2}$ outflow does not. IPCC treats human and natural $\mathrm{CO}_{2}$ differently, which is impossible.

Kohler [7] claims lower buffer capacity affects only $12 \mathrm{CO}_{2}$, not $14 \mathrm{CO}_{2}$. That claim violates chemistry and physics. Segalstad [10] previously showed Kohler's claim is impossible because "chemical and isotropic experiments show the equilibrium between $\mathrm{CO}_{2}$ and water is obtained within a few hours."

The IPCC Bern model is based upon the invalid assumption that human $\mathrm{CO}_{2}$ decreases buffer capacity.

\subsection{Isotope Data Support the Physics Model}

IPCC [3] writes:

Third, the observed isotropic trends of $13 \mathrm{C}$ and $14 \mathrm{C}$ agree qualitatively with those expected due to the $\mathrm{CO}_{2}$ emissions from fossil fuels and the biosphere, and they are quantitatively consistent with results from carbon cycle modeling.

Human fossil-fuel $\mathrm{CO}_{2}$ is " $14 \mathrm{C}$-free" and the $14 \mathrm{C}$ balance level has decreased. IPCC [3] and Kohler [7] claim this proves human $\mathrm{CO}_{2}$ caused all the rise in atmospheric $\mathrm{CO}_{2}$.

But neither IPCC nor Kohler argue with numbers. Let's do the calculations to compare the results from both models with the data. IPCC [2] says human $\mathrm{CO}_{2}$ comprises 32 percent of atmospheric $\mathrm{CO}_{2}$ while the Physics Model (12) says human $\mathrm{CO}_{2}$ is less than $5 \%$. The question is whether the available isotope data support or reject either of the models.

RealClimate [39] says the $13 \mathrm{C} / 12 \mathrm{C}$ ratio for human $\mathrm{CO}_{2}$ is about 98 percent of the ratio in natural $\mathrm{CO}_{2}$, and the $13 \mathrm{C}$ ratio has declined about 0.15 percent since 1850 . RealClimate says this proves human $\mathrm{CO}_{2}$ caused all the increase in atmospheric $\mathrm{CO}_{2}$ since 1850 .

Human $\mathrm{CO}_{2}$ causes the new balance level of D14C and $13 \mathrm{C} / 12 \mathrm{C}$ to be:

$$
L b=L n R n+L h R h
$$

Where

$L b=$ the new balance level (of D14C or $13 \mathrm{C} / 12 \mathrm{C}$ )

$L n=$ the natural balance level $(\mathrm{D} 14 \mathrm{C}=0 ; 13 \mathrm{C} / 12 \mathrm{C}=$ $100 \%$ )

$L h=$ the human balance level $(\mathrm{D} 14 \mathrm{C}=-1000 ; 13 \mathrm{C} / 12 \mathrm{C}=$ 98\%)

$R n=$ the fraction of natural $\mathrm{CO}_{2}$

$R h=$ the fraction of human $\mathrm{CO}_{2}$

The Physics Model predicts for D14C:

$$
L b=(0)(0.955)+(-1000)(0.045)=-45
$$

The IPCC model predicts for D14C:

$$
L b=(0)(0.68)+(-1000)(0.32)=-320
$$

The Physics Model predicts for 13C/12C:

$$
L b=(100)(0.955)+(98)(0.045)=99.91
$$

The IPCC model predicts for $13 \mathrm{C} / 12 \mathrm{C}$ :

$$
L b=(100)(0.680)+(98)(0.320)=99.36
$$

The $14 \mathrm{C}$ data

The Physics Model (16) predicts human $\mathrm{CO}_{2}$ has lowered the balance level of $14 \mathrm{C}$ from zero to -45 . The IPCC model (17) predicts human $\mathrm{CO}_{2}$ has lowered the $14 \mathrm{C}$ balance level to -320 .

Figure 11 compares the Physics and IPCC predicted levels for human $\mathrm{CO}_{2}$ in the atmosphere.

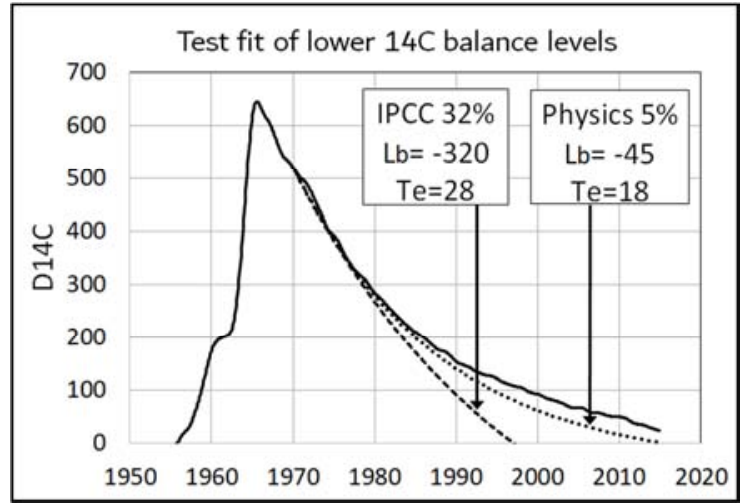

Figure 11. The dotted lines show the Physics Model calculation for a balance level of -45 . The dashed line shows the Physics Model calculation for the IPCC predicted balance level of -320 .

Figure 11 shows the Physics Model result of 5 percent human $\mathrm{CO}_{2}$ in the atmosphere matches the $14 \mathrm{C}$ data much better than the IPCC model of 32 percent of human $\mathrm{CO}_{2}$ in the atmosphere.

In summary, the $14 \mathrm{C}$ data support the Physics Model and reject the IPCC model.

The $13 \mathrm{C}$ data

The Physics Model (18) predicts human $\mathrm{CO}_{2}$ has lowered the $13 \mathrm{C}$ ratio by 0.09 . The IPCC model (19) predicts human $\mathrm{CO}_{2}$ has lowered the $13 \mathrm{C}$ ratio by 0.64 .

Figure 12 compares the Physics and IPCC predictions of the $13 \mathrm{C} / 12 \mathrm{C}$ ratio to Real Climate's numbers.

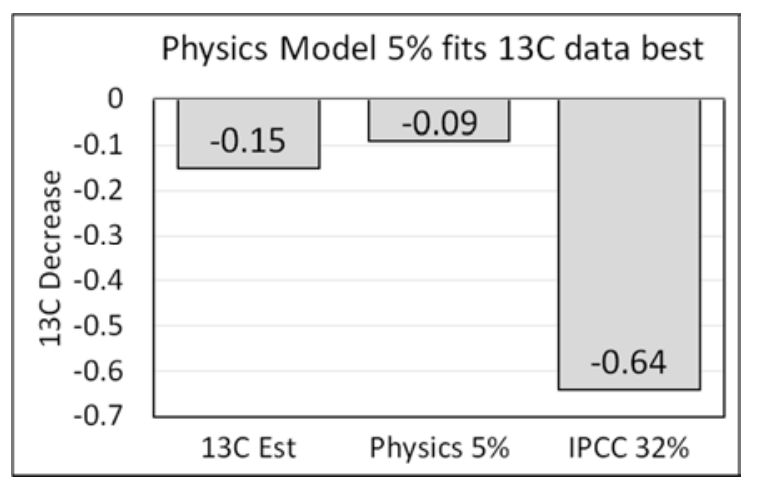

Figure 12. Real Climate [39] says the 13 C ratio has decreased by 0.15 since 1750. Physics predicts a decrease of 0.09 and IPCC predicts a decrease of 0.64 . 
There seem to be no error bounds in the available $13 \mathrm{C}$ data. Nevertheless, even without error bounds the 13C data do not support the IPCC model over the Physics Model. So, the IPCC argument fails.

Segalstad [10] calculated similar results using permil units. He concluded the isotope data show human $\mathrm{CO}_{2}$ cannot be more than 4 percent of atmospheric $\mathrm{CO}_{2}$.

\subsection{Mauna Loa Data}

Some scientists argue that a viable $\mathrm{CO}_{2}$ model must replicate the Mauna Loa $\mathrm{CO}_{2}$ data. The Physics Model can simulate the Mauna Loa data for atmospheric $\mathrm{CO}_{2}$ as well as any other model.

Spencer [40] has a model that fits the Mauna Loa data. Spencer assumes like the IPCC that the natural level of $\mathrm{CO}_{2}$ is fixed at $280 \mathrm{ppm}$ and human $\mathrm{CO}_{2}$ causes all the increase in atmospheric $\mathrm{CO}_{2}$. His model has many variables available to adjust so a fit to the Mauna Loa data is guaranteed.

The significance of the fit by the Physics Model is that it comes with physical constraints that the other models do not have. The Physics Model e-time must be 4 years and natural $\mathrm{CO}_{2}$ must be 95 percent of atmospheric $\mathrm{CO}_{2}$.

Figure 13 shows how the Physics Model fits the Mauna Loa data.

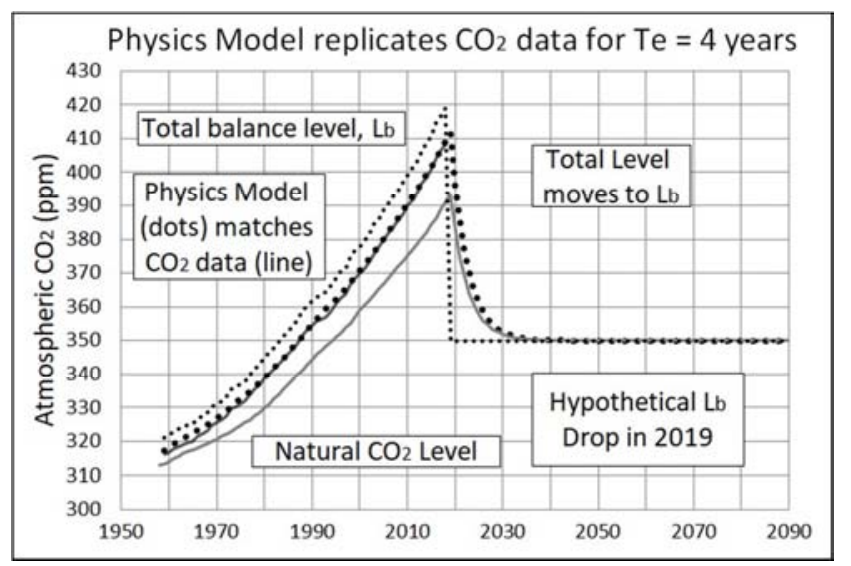

Figure 13. The Physics Model replicates the Mauna Loa data with an e-time of 4 years and the requirement that natural $\mathrm{CO}_{2}$ is 95 percent of atmospheric $\mathrm{CO}_{2}$.

In Figure 14, the total balance level is the sum of natural and human balance levels. The balance level continues to rise. Level follows the balance level with a lag of about 4 years (the e-time), after the year 2000. This lag keeps the level about 10 ppm below the its balance level. Human $\mathrm{CO}_{2}$ adds to the natural level to produce the total level, about $15 \mathrm{ppm}$ above the natural level.

In 2019, the balance level in Figure 14 is artificially reset to $350 \mathrm{ppm}$ to test how fast the $\mathrm{CO}_{2}$ level moves to the new balance level. The total $\mathrm{CO}_{2}$ level falls to its new balance level of $350 \mathrm{ppm}$ in about 10 years. $\mathrm{No}^{\mathrm{CO}_{2}}$ remains stuck in the atmosphere.

\subsection{Ice-core Data}

IPCC claims "the observational $\mathrm{CO}_{2}$ records from ice cores ... show that the maximum range of natural variability about the mean of $280 \mathrm{ppm}$ during the past 1000 years was small."

Using this invalid claim, IPCC assumes natural $\mathrm{CO}_{2}$ emissions remained constant within about one percent. IPCC's invalid claim about ice-core data is the basis of IPCC's invalid claim that human $\mathrm{CO}_{2}$ causes all the increase in atmospheric $\mathrm{CO}_{2}$ above $280 \mathrm{ppm}$. This increase is presently $130 \mathrm{ppm}$ or 32 percent.

Siegenthaler and Joos [30] observed that ice-core data show natural $\mathrm{CO}_{2}$ increased by 17 ppm or 6 percent before 1900 , when human $\mathrm{CO}_{2}$ emissions totaled only $5 \mathrm{ppm}$. These ice-core data contradict IPCC's claim that natural $\mathrm{CO}_{2}$ emissions stayed constant after 1750 .

Jaworoski [12] explains why ice-core data do not properly represent past atmospheric $\mathrm{CO}_{2}$. He concludes nature produces 97 percent of atmospheric $\mathrm{CO}_{2}$.

Proxy ice-core values for $\mathrm{CO}_{2}$ remained low for the past 650,000 years $[10,12]$. If these ice-core values represent atmospheric $\mathrm{CO}_{2}$, then atmospheric $\mathrm{CO}_{2}$ did not cause any of the global warming in the last 650,000 years. And if $\mathrm{CO}_{2}$ did not cause global warming in the past, then the IPCC has lost its claim that $\mathrm{CO}_{2}$ causes present global warming [12].

Leaf stomata and chemical data prove the historical $\mathrm{CO}_{2}$ level was much higher than derived from ice cores [12]. There is no evidence that the pre-industrial $\mathrm{CO}_{2}$ level was $280 \mathrm{ppm}$ as IPCC assumes.

Beck [13] reconstructed $\mathrm{CO}_{2}$ from chemical data show the level reached $440 \mathrm{ppm}$ in 1820 and again in 1945.

IPCC's claim that human $\mathrm{CO}_{2}$ produces all the increase in atmospheric $\mathrm{CO}_{2}$ above $280 \mathrm{ppm}$ is invalid. In science, when data contradict a theory, the theory false. The IPCC, however, ignores how its theories contradict data.

\section{Theories Must Be Logical}

\subsection{IPCC's Response Times Fail Physics}

The Physics Model e-time has a precise definition: e-time is the time for the level to move $(1-1 / \mathrm{e})$ of the distance to its balance level.

Segalstad [10] observes IPCC [3] uses many definitions of lifetime - like residence time, transit time, response time, e-folding time, and adjustment time - in its quest to prove human $\mathrm{CO}_{2}$ remains in the atmosphere for hundreds of years. Many investigators, from 1957 to 1992 , have calculated the e-time of atmospheric $\mathrm{CO}_{2}$ is about 5 years [10].

IPCC [3] defines "adjustment time ( $\mathrm{Ta})$ " as:

The time-scale characterising the decay of an instantaneous pulse input into the reservoir.

Cawley [5] defines "adjustment time (Ta)" as:

The time taken for the atmospheric $\mathrm{CO}_{2}$ concentration to substantially recover towards its original concentration following a perturbation.

The word "substantially" is imprecise.

Cawley follows IPCC to define "residence time (Tr)" as:

The average length of time a molecule of $\mathrm{CO}_{2}$ remains in the atmosphere before being taken up by the oceans or terrestrial 
biosphere.

Some authors use "residence time" to mean "e-time" but other authors, such as Cawley and IPCC, have a different meaning for residence time. This paper uses e-time because its definition is precise.

In summary, IPCC uses two different response times when it should use only e-time:

1. When the level is far from its balance level (which can be zero), IPCC thinks e-time is an adjustment time because the level is moving rapidly toward its balance level.

2. When the level is close to its balance level, IPCC thinks e-time is a residence time because "molecules" are flowing in and out with little change in level.

Figure 14 illustrates how e-time relates to IPCC's adjustment and residence times.

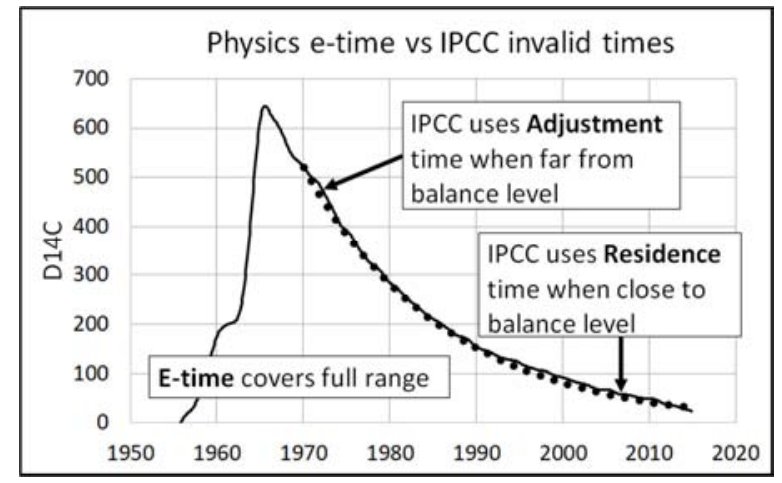

Figure 14. E-time covers the full range of movement of level to a balance level. IPCC [3] adjustment and residence times apply to only each end of the range.

IPCC defines "turnover time $(T t)$ " as:

The ratio of the mass $M$ of a reservoir (e.g., a gaseous compound in the atmosphere) and the total rate of removal $S$ from the reservoir: $T t=M / S$.

IPCC's turnover time seems to be the same as e-time except "removal" is not the same as outflow. Near the balance level, IPCC sometimes interprets "removal" to mean the difference between outflow and inflow.

IPCC says when outflow is proportional to level (the Physics Model hypothesis) then adjustment time equals turnover time. IPCC claims:

In simple cases, where the global removal of the compound is directly proportional to the total mass of the reservoir, the adjustment time equals the turnover time: $T a=T t$.

The Physics Model's replication of the 14C data shows the $14 \mathrm{CO}_{2}$ outflow is proportional to level. Therefore, by IPCC's own definition, adjustment time equals e-time equals residence time.

IPCC says in further confusion:

In more complicated cases, where several reservoirs are involved or where the removal is not proportional to the total mass, the equality $T=$ Ta no longer holds.

Carbon dioxide is an extreme example. Its turnover time is only about 4 years because of the rapid exchange between atmosphere and the ocean and terrestrial biota.

Although an approximate value of 100 years may be given for the adjustment time of $\mathrm{CO}_{2}$ in the atmosphere, the actual adjustment is faster initially and slower later on.

IPCC agrees $12 \mathrm{CO}_{2}$ turnover time (e-time) is about 4 years. IPCC claims adjustment time is "fast initially and slower later on" which is why its Bern model cannot replicate the $14 \mathrm{C}$ data in Figure 9.

The $14 \mathrm{C}$ data show the e-time for $14 \mathrm{CO}_{2}$ is 16.5 years. This e-time is the upper bound for $12 \mathrm{CO}_{2}$ e-time. The IPCC claim of hundreds of years is based on IPCC's misunderstanding of e-time.

Unfortunately, there are many different definitions of residence time. Therefore, this paper uses e-time with its exact definition.

\subsection{IPCC's First Core Argument Is Illogical}

The IPCC [2] first core argument notes that human emissions from 1750 to 2013 totaled $185 \mathrm{ppm}$ while atmospheric $\mathrm{CO}_{2}$ increased by only $117 \mathrm{ppm}$. These numbers are OK. But IPCC claims this proves human $\mathrm{CO}_{2}$ caused all the increase in atmospheric $\mathrm{CO}_{2}$ above $280 \mathrm{ppm}$. IPCC's logic is faulty.

Figure 15 shows the IPCC first core argument.

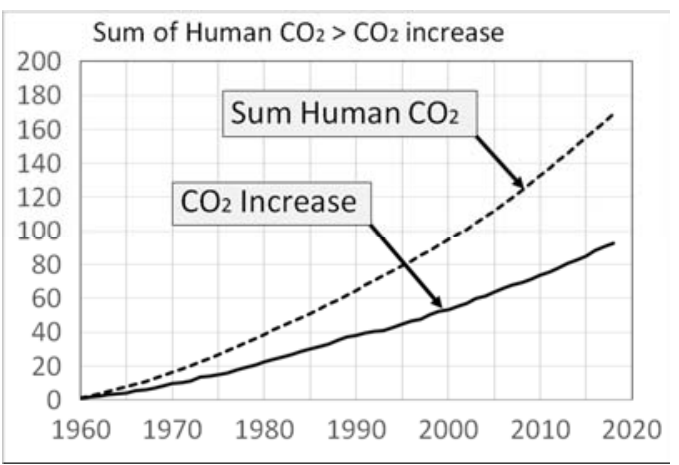

Figure 15. The sum of human $\mathrm{CO}_{2}$ year-by-year is larger than the increase in atmospheric $\mathrm{CO}_{2}$.

However, the fact that the sum of human emissions is greater than the increase does not prove human $\mathrm{CO}_{2}$ caused the increase. The IPCC argument omits natural $\mathrm{CO}_{2}$ which totaled about $6000 \mathrm{ppm}$ during the same period, much larger than the sum of human $\mathrm{CO}_{2}$.

Figure 16 shows the plot when the sum of natural $\mathrm{CO}_{2}$ is included.

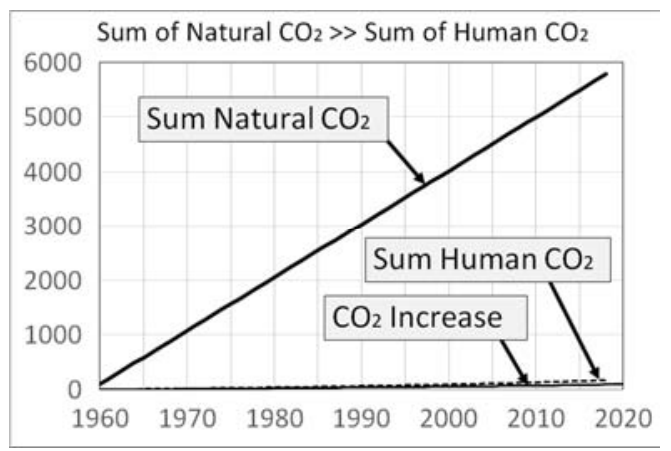

Figure 16. The sum of natural $\mathrm{CO}_{2}$ compared to the sum of human $\mathrm{CO}_{2}$ and the increase in $\mathrm{CO}_{2}$ 
The sum of natural $\mathrm{CO}_{2}$ from 1959 to 2018 is 5700 . The sum of human $\mathrm{CO}_{2}$ over the same period is $170 \mathrm{ppm}$ which is 3 percent of the natural $\mathrm{CO}_{2}$ sum. IPCC's whole case depends upon its incorrect assumption that nature did not vary more that 3 percent since 1959 or since 1750 . At the same time, IPCC admits it does not know nature's $\mathrm{CO}_{2}$ emission within 50 percent.

The fundamental error in this IPCC argument is discussed in Section 3.1. The sums of inflows do not matter because inflows do not "add" to atmospheric $\mathrm{CO}_{2}$. Inflows set balance levels. The human effect on the total balance level is less than 5 percent.

\subsection{IPCC's Second Core Argument Is Illogical}

IPCC [2] claims nature has been a "net carbon sink" since 1750 , so nature could not have caused the observed rise in atmospheric carbon dioxide. Please refer to Figure 5 that shows the inflow and outflow of atmospheric $\mathrm{CO}_{2}$.

Of course, nature is a "net carbon sink" because nature absorbs human $\mathrm{CO}_{2}$ emissions. However, absorption of human $\mathrm{CO}_{2}$ has no bearing whatsoever on how much natural $\mathrm{CO}_{2}$ flows into the atmosphere. Nature can set its inflow as it pleases, no matter how much human inflow nature absorbs. The 98-ppm natural flow can double or reduce to one-half while nature continues to absorb the outflow of the human addition to atmospheric $\mathrm{CO}_{2}$. So, the IPCC argument is absurd.

The Physics Model shows how $\mathrm{CO}_{2}$ inflows set balance levels in atmospheric $\mathrm{CO}_{2}$. At the balance level, outflow will equal inflow. No $\mathrm{CO}_{2}$ gets trapped in the atmosphere.

\subsection{Key IPCC Paper Makes Serious Errors}

Kohler [7] uses Cawley [5] to "prove" the IPCC case. But Cawley fails physics and statistics.

Cawley [5] is a key paper for the IPCC theory. Cawley claims human $\mathrm{CO}_{2}$ caused all the increase of atmospheric $\mathrm{CO}_{2}$ above the $280 \mathrm{ppm}$ in 1750. But Cawley's attempted proof fails physics.

Figure 17 shows three of Cawley's equations.

$\begin{aligned} F_{e} & =k_{e} C+F_{e}^{0} \\ \frac{d C_{A}}{d t} & =-\frac{C_{A} F_{e}}{C} \\ \frac{d C_{N}}{d t} & =F_{i}^{0}-\frac{C_{N} F_{e}}{C}\end{aligned}$

Figure 17. Equations from Cawley [5].

Cawley's equation (3) attempts to do the same job as Physics Model (2), namely, to represent how level sets outflow. But Cawley adds to his equation (3) a second term that represents a steady-state outflow that is independent of level. Cawley's added term is fictitious because his first term on the right side of his equation (3) is the true source of all outflow. As a result, all Cawley's equations after his (3) are wrong, which makes his whole paper wrong.
Cawley's equation (7) should include his $\mathrm{Fa}$ for human inflow. His equations (7) and (8) should omit his arbitrary Fe for outflow and set outflow equal to level (his $\mathrm{C}$ ) divided by his residence time. His residence time is also inaccurate as shown in Section 6.1.

\subsection{Statistical Correlation}

Cawley [5] argues,

Lastly, the rise in atmospheric carbon dioxide closely parallels the rise in anthropogenic emissions ... which would be somewhat of a coincidence if the rise were essentially natural in origin!

IPCC [3] writes:

Second, the observed rate of $\mathrm{CO}_{2}$ increase closely parallels the accumulated emission trends from fossil fuel combustion and from land use changes.

IPCC incorrectly claims this proves human $\mathrm{CO}_{2}$ causes the increase in atmospheric $\mathrm{CO}_{2}$.

A standard scientific test for the non-existence of cause and effect is to show the correlation, of the assumed cause with the assumed effect, is zero.

For the IPCC to argue that human $\mathrm{CO}_{2}$ causes climate change, the IPCC must show that the correlation of human emissions with the increase in atmospheric $\mathrm{CO}_{2}$ is significantly greater than zero.

Proper statistics requires a detrended analysis of a time series to conclude cause and effect. Munshi [41] shows the "detrended correlation of annual emissions with annual changes in atmospheric $\mathrm{CO}_{2}$ " is zero. Chaamjamal [42] extended Munshi's calculations and found the correlations are zero for time intervals from one to five years.

Therefore, the standard statistical test for cause and effect proves human $\mathrm{CO}_{2}$ is insignificant to the increase in atmospheric $\mathrm{CO}_{2}$.

The ratio of annual change in atmospheric $\mathrm{CO}_{2}$ to annual human $\mathrm{CO}_{2}$ emissions that Munshi [41] tested is IPCC's "airborne fraction". Therefore, IPCC's airborne fraction has no useful meaning.

An estimate of the airborne fraction is about $2.5 \mathrm{ppm} / \mathrm{year}$ divided by $5 \mathrm{ppm} / \mathrm{year}$, or 0.5 . Since the increase in level is caused by an increase in natural $\mathrm{CO}_{2}$ emissions, the airborne fraction has little physical meaning, and it would go to infinity if human emissions stopped.

\section{Conclusions}

The IPCC model and the Physics model compete to describe how human $\mathrm{CO}_{2}$ emissions add to atmospheric $\mathrm{CO}_{2}$. Both models agree that the $\mathrm{CO}_{2}$ inflow into the atmosphere is less than 5 percent human $\mathrm{CO}_{2}$ and more than 95 percent natural $\mathrm{CO}_{2}$.

The IPCC model concludes that human $\mathrm{CO}_{2}$ causes all the increase in atmospheric $\mathrm{CO}_{2}$ above $280 \mathrm{ppm}$; that 15 percent of all human $\mathrm{CO}_{2}$ emissions stays in the atmosphere forever; that 53 percent stays for hundreds of years; and only 32 percent flows freely out of the atmosphere like natural $\mathrm{CO}_{2}$.

The Physics Model treats human $\mathrm{CO}_{2}$ and natural $\mathrm{CO}_{2}$ the 
same because their $\mathrm{CO}_{2}$ molecules are identical. The Physics model makes only one hypothesis: $\mathrm{CO}_{2}$ outflow equals the level of $\mathrm{CO}_{2}$ in the atmosphere divided by e-time.

The Physics Model concludes that inflow sets a balance level equal to inflow multiplied by e-time, and that continuing inflow does not continue to increase atmospheric $\mathrm{CO}_{2}$. Rather inflow sets a balance level where outflow equals inflow and continuing inflow will not further increase the level of atmospheric $\mathrm{CO}_{2}$ beyond the balance level.

The proper test of two theories is not to claim the IPCC theory explains "observational evidence." The proper test is the scientific method: if a prediction is wrong, the theory is wrong.

The 14C data following the cessation of the atomic bomb tests show how the level of $\mathrm{CO}_{2}$ in the atmosphere returns to its balance level after inflow decreases. All valid models of atmospheric $\mathrm{CO}_{2}$ must be able to replicate the $14 \mathrm{C}$ data.

The Physics Model exactly replicates the $14 \mathrm{C}$ data after 1970. This replication shows the e-time for $14 \mathrm{CO}_{2}$ is 16.5 years and that this e-time has been constant since 1970. The replication shows the Physics Model hypothesis - that outflow equals level divided by e-time - is correct.

The IPCC Bern model cannot replicate the $14 \mathrm{C}$ data. Its curve crosses the $14 \mathrm{C}$ data curve. The Bern model cannot even replicate itself if it is restarted at any point. This failure proves the IPCC Bern model does not have the mathematical structure for a valid model.

If natural $\mathrm{CO}_{2}$ is inserted into the Bern model, as physics requires, the Bern model predicts that 15 percent of natural $\mathrm{CO}_{2}$ inflow sticks in the atmosphere forever, which contradicts data and proves the Bern model is invalid.

The Physics Model concludes that the ratio of human to natural $\mathrm{CO}_{2}$ in the atmosphere equals the ratio of their inflows, independent of e-time, and that the e-times for both human and natural $\mathrm{CO}_{2}$ are the same. Using IPCC data, the e-time for $12 \mathrm{CO}_{2}$ is about 4 years.

The ratio conclusion means human $\mathrm{CO}_{2}$ adds only about 18 ppm and natural $\mathrm{CO}_{2}$ adds about 392 ppm to today's $\mathrm{CO}_{2}$ level of $410 \mathrm{ppm}$. If all human $\mathrm{CO}_{2}$ emissions stopped and natural $\mathrm{CO}_{2}$ emissions stayed constant, then the level of atmospheric $\mathrm{CO}_{2}$ would fall only to $392 \mathrm{ppm}$ in about 10 years. Nothing would be gained by stopping human $\mathrm{CO}_{2}$ emissions. There are no long-term effects of human $\mathrm{CO}_{2}$ emissions. Continued constant $\mathrm{CO}_{2}$ emissions do not add more $\mathrm{CO}_{2}$ to the atmosphere. Continued constant $\mathrm{CO}_{2}$ emissions simply maintain the balance level.

\section{Acknowledgements}

The author thanks Chuck Wiese, Laurence Gould, Tom Sheahen, Charles Camenzuli, and others who reviewed this paper and provided scientific critique and suggestions. The author thanks Daniel Nebert, Gordon Danielson, and Valerie Berry, who provided language and grammar suggestions.

This research did not receive any grant from funding agencies in the public, commercial, or not-for-profit sectors. This research was funded solely by the personal funds of the author.

\section{Author's Contributions}

The author declares he is the only contributor to the research in this paper.

\section{Downloads}

Download supporting files.

\section{References}

[1] USGCRP, 2017: Climate Science Special Report: Fourth National Climate Assessment, Volume I. U.S. Global Change Research Program, Washington, DC, USA, 470 pp; 2018. doi: 10.7930/J0J964J6. https://science2017.globalchange.gov/

[2] IPCC, 2001: Working Group 1: The scientific basis. The Carbon Cycle and Atmosphere $\mathrm{CO}_{2}$. https://www.ipcc.ch/site/assets/uploads/2018/02/TAR-03.pdf

[3] IPCC, 2007: Climate Change 2007: The Physical Science Basis. https://www.ipcc.ch/site/assets/uploads/2018/05/ar4_wg1_full report-1.pdf

[4] D. Archer, M. Eby, V. Brovkin, A. Ridgwell, L. Cao, U. Mikolajewicz, et al., "Atmospheric Lifetime of Fossil Fuel Carbon Dioxide”. Annu. Rev. Earth Planet. Sci., 37, pp. 117134; 2009.

https://www.annualreviews.org/doi/pdf/10.1146/annurev.earth. 031208.100206

[5] G. C. Cawley, "On the Atmospheric residence time of anthropogenically sourced $\mathrm{CO}_{2}$ ". Energy Fuels 25, pp. 55035513; 2011. http://dx.doi.org/10.1021/ef200914u

[6] Z. Kern, M. Leuenberger, Comment on "The phase relation between atmospheric $\mathrm{CO}_{2}$ and global temperature" by Humlum et al. Glob. Planet. Change 100: 51-69.: Isotopes ignored. Glob. Planet. Chang. 109, 1-2; 2013.

https://dx.doi.org/10.1016/j.gloplacha.2013.07.002

[7] P. Kohler, J. Hauck, C. Volker, D. A. Wolf-Gladrow, M. Butzin, J. B. Halpern, et al. Comment on "Scrutinizing the carbon cycle and $\mathrm{CO}_{2}$ residence time in the atmosphere" by H. Harde, Global and Planetary Change; 2017.

https://www.soest.hawaii.edu/oceanography/faculty/zeebe file s/Publications/KoehlerGPC17.pdf

[8] R. Revelle, H. Suess, " $\mathrm{CO}_{2}$ exchange between atmosphere and ocean and the question of an increase of atmospheric $\mathrm{CO}_{2}$ during past decades". Tellus. 9: 18-27; 1957. http://onlinelibrary.wiley.com/doi/10.1111/j.2153-3490.1957.t b01849.x/abstract.

[9] C. Starr, "Atmospheric $\mathrm{CO}_{2}$ residence time and the carbon cycle". Science Direct, 18, 12, pp. 1297-1310; 1992. https://www.sciencedirect.com/science/article/pii/0360544293 900178

[10] T. V. Segalstad, "Carbon cycle modelling and the residence time of natural and anthropogenic atmospheric $\mathrm{CO}_{2}$ : on the construction of the "Greenhouse Effect Global Warming" dogma". In: Bate, R. (Ed.): Global warming: the continuing debate. ESEF, Cambridge, U. K. [ISBN 0952773422]: 184-219; 1998. http://www.CO ${ }_{2}$ web.info/ESEF3VO2.pdf 
[11] Z. Jaworowski, "Climate Change: Incorrect information on pre-industrial $\mathrm{CO}_{2}$ ". Statement written for the Hearing before the US Senate Committee on Commerce, Science, and Transportation. 2003.

http://www.mitosyfraudes.org/Calen5/JawoCO ${ }_{2}$-Eng.html

[12] Z. Jaworowski, " $\mathrm{CO}_{2}$ : The Greatest Scientific Scandal of our Time". 21st CENTURY Science \& Technology. 2007. https://21sci-tech.com/Articles\%202007/20_1-2_CO__Scandal .pdf

[13] E. Beck, "180 Years of Atmospheric $\mathrm{CO}_{2}$ Gas Analysis by Chemical Methods". Energy \& Environment. Vol 18, No. 2. 2007.

https://21sci-tech.com/Subscriptions/Spring\%202008\%20ON LINE/ $/ \mathrm{CO}_{2}$ chemical.pdf

[14] A. Rorsch, R.S. Courtney, D. Thoenes, "The Interaction of Climate Change and the $\mathrm{CO}_{2}$ Cycle". Energy \& Environment, Volume $16, \quad$ No 2 2; 2005. https://journals.sagepub.com/doi/pdf/10.1260/0958305053749 589

[15] R.S. Courtney, "Limits to existing quantitative understanding of past, present and future changes to atmospheric $\mathrm{CO}_{2}$ concentration". International Conference on Climate Change, New York. 2008.

https://www.heartland.org/multimedia/videos/richard-courtney -iccc1

[16] T, Quirk, "Sources and sinks of $\mathrm{CO}_{2}$ ". Energy \& Environment. Volume: 20 Issue: 1, pp. 105-121. 2009. https://journals.sagepub.com/doi/10.1260/0958305097876891 23

[17] R. E. Essenhigh, "Potential dependence of global warming on the residence time (RT) in the atmosphere of anthropogenically sourced $\mathrm{CO}_{2}$ ”. Energy Fuel 23, pp. 2773-2784; 2009. https://pubs.acs.org/doi/abs/10.1021/ef800581r

[18] J. A. Glassman, "On why $\mathrm{CO}_{2}$ is known not to have accumulated in the atmosphere and what is happening with $\mathrm{CO}_{2}$ in the modern era". Rocket Scientist Journal; 2010. https://www.rocketscientistsjournal.com/2007/06/on_why_CO 2_is_known_not_to_hav.html\#more

[19] M. L. Salby, "Physics of the Atmosphere and Climate". Cambridge University Press. 2012. (ISBN: 978-0-521-76718-7) https://www.amazon.com/Physics-Atmosphere-Climate-Murr $\mathrm{y}$-Salby/dp/0521767180/ref=mt hardcover? encoding $=$ UTF8 $\& m e=$

[20] M. L. Salby, "Relationship Between Greenhouse Gases and Global Temperature". Video Presentation, April 18, 2013. Helmut-Schmidt-University Hamburg. https://www.youtube.com/watch?v=2ROw_cDKwc0

[21] M. L. Salby, "Atmosphere Carbon". Video Presentation, July 18, 2016. University College London. https://www.youtube.com/watch?v=3q-M_uYkpT0\&feature= youtu.be

[22] M. L. Salby, "What is really behind the increase in atmospheric $\mathrm{CO}_{2}$ ?" Video Presentation, October 10, 2018. Helmut-Schmidt-University Hamburg, Germany. https://www.youtube.com/watch?time_continue $=10 \& v=$ rohF6 K2avtY

[23] O. Humlum, K. Stordahl, J.E. Solheim, "The phase relation between atmospheric $\mathrm{CO}_{2}$ and global temperatures". Global and Planetary Change, 100, pp 51-69, 2013.
https://www.sciencedirect.com/science/article/pii/S092181811 2001658

[24] H. Harde, "Scrutinizing the carbon cycle and $\mathrm{CO}_{2}$ residence time in the atmosphere". Global and Planetary Change. 152, 19-26; 2017.

https://www.sciencedirect.com/science/article/pii/S092181811 6304787.

[25] H. Harde, "What Humans Contribute to Atmospheric $\mathrm{CO}_{2}$ : Comparison of Carbon Cycle Models with Observations". Earth Sciences Vol. 8, No. 3, 2019, pp. 139-159. doi: 10.11648/j.earth.20190803.13 http://www.sciencepublishinggroup.com/journal/paperinfo?jo urnalid $=161 \&$ doi $=10.11648 /$ j.earth.20190803.13, http://article.esjournal.org/pdf/10.11648.j.earth.20190803.13.p df

[26] E. X Berry, “A fatal flaw in global warming science". Basic Science of a Changing Climate. Porto University, Portugal. Sep $7 ; 2018$.

https://www.portoconference2018.org/uploads/1/1/7/3/117342 822/11_edwinberryportosep 7 final.pdf

[27] E. X Berry, "Contradictions to IPCC's climate change theory". Annual meeting of the American Meteorological Society, Phoenix; 2019.

https://ams.confex.com/ams/2019Annual/meetingapp.cgi/Pape $\mathrm{r} / 349565$

[28] T. Boden, B. Andres, (2017) Global $\mathrm{CO}_{2}$ emissions from fossil-fuel burning, cement manufacture, and gas flaring: 1751-2014.

http://cdiac.ornl.gov/ftp/ndp030/global.1751_2014.ems.

[29] H. B. Dwight, "Tables of Integrals and Other Mathematical Data” Item 90.1. MacMillian Company; 1955. https://www.amazon.com/Tables-Integrals-Other-Mathematica 1-Data/dp/0023311703

[30] U. Siegenthaler, F. Joos, "Use of a simple model for studying oceanic tracer distributions and the global carbon cycle". Tellus, 44B, 186-207; 1992.

https://onlinelibrary.wiley.com/doi/10.1034/j.1600-0889.1992. t01-2-00003.x/epdf

[31] E. Maier-Reimer, L. Hasselmann, "Transport and storage of $\mathrm{CO}_{2}$ in the ocean - an inorganic ocean-circulation carbon cycle model". Climate Dynamics 2 (2):63-90; 1987. DOI: 10.1007/BF01054491

[32] F. Joos, R. Roth, J. S. Fuglestvedt, G. P. Peters, I. G. Enting, von Bloh, et al. "Carbon dioxide and climate impulse response functions for the computation of greenhouse gas metrics: a multi-model analysis". Atmospheric Chemistry and Physics 13 (5), doi: 10.5194/acpd-12-19799-2012. Atmos. Chem. Phys. 13 , 2793-2825;

2013. https://www.atmos-chem-phys.net/13/2793/2013/acp-13-2793 -2013.pdf

https://www.researchgate.net/publication/235431147_Carbon dioxide_and_climate_impulse_response_functions_for_the_co mputation_of_greenhouse_gas_metrics_A_multi-model_analy sis

[33] F. Joos, "Parameters for tuning a simple carbon cycle model". 2002. https://unfccc.int/resource/brazil/carbon.html

[34] Q. Hua, M. Barbetti, A. Z. Rakowski. "Atmospheric radiocarbon for the period 1950-2010". RADIOCARBON, Vol 55, pp. 2059-2072. Table S2c. 2013. https://doi.org/10.2458/azu_js_rc.v55i2.16177 
[35] J. C. Turnbull, S. E. Mikaloff Fletcher, I. Ansell, G. W. Brailsford, R. C. Moss, Norris, et al. "Sixty years of radiocarbon dioxide measurements at Wellington, New Zealand: 1954-2014”. Atmos. Chem. Phys., 17, pp. 1477114784. 2017. https://doi.org/10.5194/acp-17-14771-2017

[36] I. Levin, T. Naegler, B. Kromer, M. Diehl, R. Francey, A. Gomez-Pelaez, et al., "Observations and modelling of the global distribution and long-term trend of atmospheric $14 \mathrm{CO}_{2}$ ". Tellus B: Chemical and Physical Meteorology. 2010. https://www.tandfonline.com/doi/abs/10.1111/j.1600-0889.200 9.00446.x

[37] Wikipedia: Isotopes. https://simple.m.wikipedia.org/wiki/Isotope

[38] A. P. Ballantyne, C. B. Alden, J. B. Miller, P. P. Tans, J. W. C. White, "Increase in observed net carbon dioxide uptake by land and oceans during the past 50 years", Nature 488, pp. 70-73, 2012. doi:10.1038/nature11299.

https://www.researchgate.net/publication/230615762_Increase in_observed_net_carbon_dioxide_uptake_by_land_and_ocea ns_during_the_past_50_years
[39] RealClimate, "How do we know that recent $\mathrm{CO}_{2}$ increases are due to human activities?". 2004. http://www.realclimate.org/index.php/archives/2004/12/how-d o-we-know-that-recent-cosub2sub-increases-are-due-to-huma n-activities-updated/

[40] R. Spencer, "A simple model of the atmospheric $\mathrm{CO}_{2}$ budget". 2019.

http://www.drroyspencer.com/2019/04/a-simple-model-of-theatmospheric- $\mathrm{CO}_{2}$-budget/

[41] J. Munshi, "Responsiveness of atmospheric $\mathrm{CO}_{2}$ to fossil fuel emissions: Updated". SSRN; 2017.

https://papers.ssrn.com/sol3/papers.cfm?abstract id=2997420

[42] Chaamjamal, "Fossil fuel emissions and atmospheric composition". Thongchai Thailand. 2019. https://tambonthongchai.com/2018/12/19/ $\mathrm{CO}_{2}$ responsiveness/ 